\title{
Hepatic Encephalopathy Secondary to Chronic Liver Lesions Caused by Crotalaria incana in a Bovine
}

\author{
Paula Velozo Leal', Gleice Kelli Ayardes de Melo ${ }^{1}$, Arnildo Pott' ${ }^{2}$, Tessie Beck Martins ${ }^{3}$, Dale Gardner ${ }^{4}$, \\ Claudio Severo Lombardo de Barros ${ }^{3}$ \& Ricardo Antônio Amaral de Lemos ${ }^{3}$
}

\begin{abstract}
Background: Crotalaria spp. Poisoning induces liver or pulmonary disease. C. mucronata, C. juncea, C. spectabilis, and C. retusa are the Crotalaria spp. inducing spontaneous intoxication in livestock in Brazil. C. mucronata and C. juncea are associated with interstitial pneumonia, while $C$. retusa and $C$. specatabilis induce hepatotoxicosis. The toxic principle in Crotalaria spp. are dehydropyrrolizidine alkaloids and their $N$-oxides. $C$. incana poisoning to livestock is rarely documented. This paper reports the clinical signs and pathological findings of a case of Crotalaria incana poisoning in a steer. The chemical finding of a potential toxic dehydropyrrolizidine alkaloid in the plant is documented for the first time. Case: The affected bovine was part of a herd of 80 two-year-old steers that were transferred from Property 1 to Property 2, 30 days prior to the event. In the pasture of Property I - where the steers were held for 6 months - there was a heavy infestation by a Crotalaria species with signs of being consumed by the steers. The plant was identified as Crotalaria incana at the Botanical Laboratory of the Federal University of Mato Grosso do Sul and a voucher specimen was filed there under the register GCMS 51169. Two days after entering Property 2 one of the steers became depressed, staggering, and in poor body condition. With time, the steer became oblivious to the environment and died 20 days after the onset of the clinical signs. Significant necropsy findings were limited to the liver which was markedly enlarged and with rounded edges. The hepatic cut surface was mottled with dark red and extensive orange areas of discoloration. The gallbladder was distended and the bile was inspissated. Microscopically, in the liver, there was fibrosis, bile duct hyperplasia and hepatocellular megalocytosis. The Glisson's capsule was markedly thickened by fibrosis. In the brain, there was vacuolation of myelin sheaths (status spongiosus), moderate gliosis, and rare Alzheimer type 2 astrocytes.

Discussion: The diagnosis of intoxication by $C$. incana was based on clinical signs and pathological changes and the evidence of the plant being consumed. The high infestation of $C$. incana in the pasture, the high proportion of dead matter and the low concentration of viable pasture favored the ingestion of $C$. incana. Spongy degeneration, a typical lesion of hepatic encephalopathy, was observed in the several areas of the brain. Cirrhosis of the liver as seen in the case of this report, results in elevated ammonia levels in the blood - and eventually in the brain - and ammonia toxicity causes hepatic encephalopathy. Morphological changes in hepatic encephalopathy in the central nervous system of human beings and horses centers on astrocytes which undergo Alzheimer type 2 change developing an enlarged, pale nuclei with a rim of chromatin and prominent nucleoli. Astrocytes pairs and triplets are seen, and, in severe cases, astrocytic nuclei may become lobulated and contain glycogen. Chemical analysis of $C$. incana was accomplished by acid-base extraction with zinc reduction of $N$-oxides and quantitation by spectrometry. Quantitative analysis was achieved by liquid chromatography-mass spectrometry. To confirm the identity of the alkaloid in the sample of $C$. incana the isolated alkaloid was compared to a standard sample of usaramine previously isolated, and its identity verified by magnetic resonance spectroscopy analysis. The 1,2-dehydropyrrolizidine alkaloid usaramine, as well as its $N$-oxide, were identified as the major alkaloids in in $C$. incana. The concentration found in the seed was consistent with that previously reported. This is a new finding on the toxic principle of $C$. incana.
\end{abstract}

Keywords: cattle diseases, poisonous plants, pathology, hepatotoxicity, Crotalaria incana, chronic liver failure. 


\section{INTRODUCTION}

There are several Crotalaria spp. distributed worldwide; most are poisonous for livestock, inducing liver or pulmonary disease [6,17]. C. mucronata, $C$. juncea, C. spectabilis, and C. retusa are the Crotalaria spp. causes intoxication in livestock in Brazil [16]. $C$. mucronata and $C$. juncea are associated with interstitial pneumonia, while $C$. retusa and $C$. specatabilis with hepatotoxicosis [16]. The toxic principle in Crotalaria spp. are dehydropyrrolizidine alkaloids. dehydropyrrolizidine and their $N$-oxides are present in plant families [16]. The hepatotoxic pyrrolizidine alkaloids derivatives are esters of 1-hydroxymethyl-1,2-dihydro-7-hydroxypyrrolizidine. Requirements for toxicity appear to include the 1-2 unsaturation (dehydropyrrolizidine) and the esterification with a branched-chain acid. These dehydropyrrolizidines are metabolized by Cytochrome P450 enzymes in the liver to the corresponding "pyrrole type esters", responsible for dehydropyrrolizidine-induced toxicity [14]. dehydropyrrolizidine-induced hepatotoxicity, which has long been recognized, can be acute or - more often - chronic lesions [12]. The chronic lesions consist of fibrosis, megalocytosis, and bile duct proliferation [3]. Impaired function of the liver leads to elevated ammonia levels in the blood and eventually in the brain, resulting in a neurological syndrome referred to as hepatic encephalopathy $[8,9]$.

$C$. incana poisoning to livestock is rarely documented [15]. We report here the clinical signs and pathological findings of a case of $C$. incana poisoning in a bovine and the chemical the finding of a potential toxic dehydropyrrolizidine in the plant.

\section{CASE}

Clinical and epidemiological data were collected during and on-site visits to the properties involved with these cases since the cattle had been moved from an extensive grazing system (Property 1) to a feedlot (Property 2). To determine the proportion of the various morphological components that constitute the pasture at Property 1, samples were collected through a method using a $0.5 \mathrm{~m}^{2}$ metallic square. This metallic square was placed on ten different random points of the pasture, and the vegetation was collected from each of these ten points. The samples from each square were weighted, and the specimens were separated based on their morphology. The separated parts were then weighted, and each component of the pasture was calculated.
A Crotalaria species was identified as one of the components of the pasture and specimens of the plant were sent for identification at Botanical Laboratory of the Federal University of Mato Grosso do Sul. It was identified as Crotalaria incana (Figure 1), and a voucher specimen was filed there under the register GCMS 51169.

Chemical analysis of $C$. incana was accomplished by acid-base extraction with zinc ${ }^{1}$ reduction of $\mathrm{N}$-oxides and quantitation by liquid chromatography-mass spectrometry ${ }^{2}$. A measured amount of ground plant $(2.0 \mathrm{~g})$ was extracted with $40 \mathrm{~mL}$ of methanol for $16 \mathrm{~h}$. In duplicate, a $2.0 \mathrm{~mL}$ aliquot of each extract was placed into an $8 \mathrm{~mL}$ vial and evaporated to dryness under nitrogen flow. $2.0 \mathrm{~mL}$ of $0.05 \mathrm{M}$ sulfuric acid was added and powdered $\mathrm{Zn}$ (added to set 1 only) and the solutions allowed to mix for $30 \mathrm{~min}$. The samples were centrifuged and a $1.0 \mathrm{~mL}$ of the upper acid layer was added to preconditioned Strata SCX3 ${ }^{5}$ (200 mg; pre-rinsed with $3 \mathrm{~mL}$ methanol ${ }^{3}$ and $3 \mathrm{~mL}$ water solid phase extraction columns. The samples were loaded onto the column under vaccum and then rinsed with 3 $\mathrm{mL}$ water and $3 \mathrm{~mL}$ methanol. The alkaloid fraction was eluted with $4 \mathrm{~mL}$ of ammoniated methanol ${ }^{3}$ (a 1/10

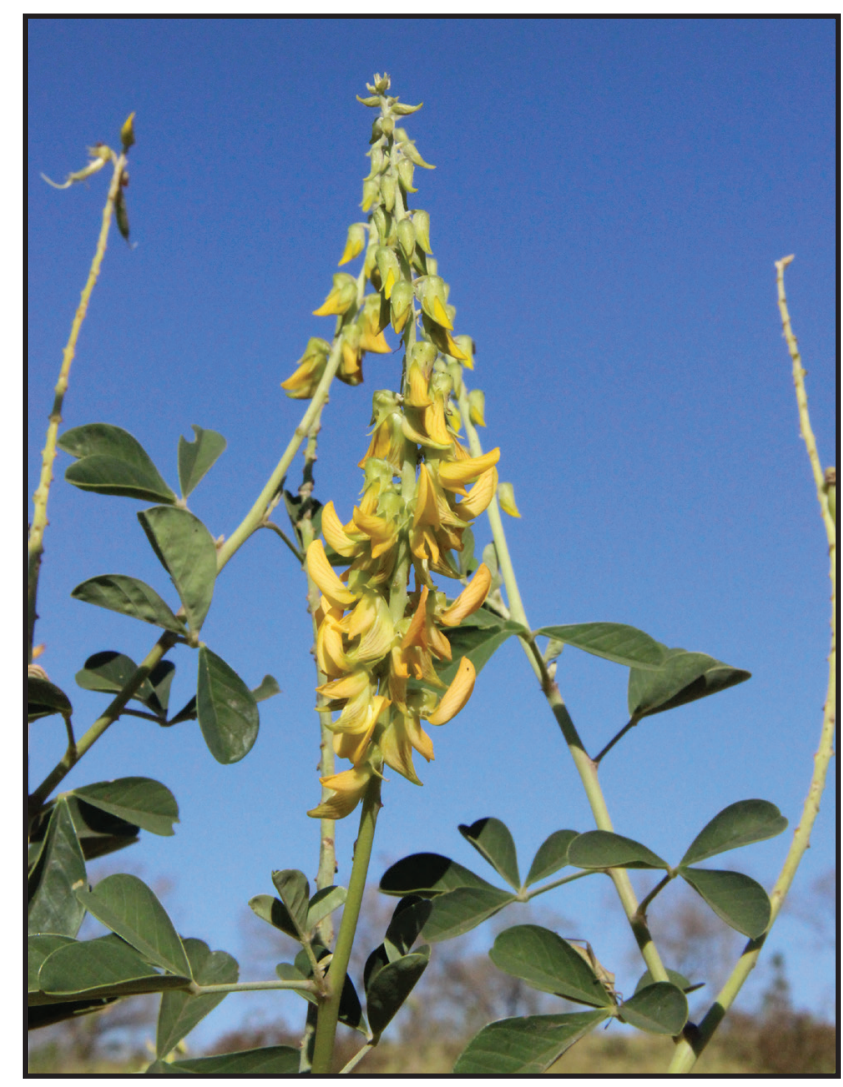

Figure 1. Flowering specimen of C. incana found in Property 1. Camapuã, MS, Brazil. 
dilution in methanol of ammonia saturated methanol ${ }^{1}$, evaporated to dryness and then taken backup in $1.0 \mathrm{~mL}$ $50 \%$ methanol (water). A $0.05 \mathrm{~mL}$ aliquot was diluted into $1.0 \mathrm{~mL}$ of $50 \%$ methanol $^{1}$ for liquid chromatography-mass spectrometry ${ }^{2}$. A set of calibration standards were prepared with usaramine standard (from the collection of standards at the Poisonous Plant Research Laboratory) to give known concentration at 5.0, 2.5, $1.25,0.625,0.156$, and $0.039 \mu \mathrm{g} / \mathrm{mL}$.

Quantitative analysis by liquid chromatography-mass spectrometry ${ }^{2}$ was achieved using a Thermo Fisher Velos LTQ spectrometer ${ }^{4}$, an Agilent 1260 binary high-performance liquid chromatography pump and autosampler ${ }^{2}$ and a Synergi Hydro $(150 \text { x } 2.0 \mathrm{~mm})^{5}$ high-performance liquid chromatography column ${ }^{5}$ and guard column of equivalent solid phase. Separation was achieved using a linear gradient of acetonitrile ${ }^{1}$ (A) and $0.1 \%$ formic acid ${ }^{1}(\mathrm{~B})$ at flow rate of $0.400 \mathrm{~mL} /$ min. Gradient conditions were 3\% (A) (0-2 min); 3\% A increased to $70 \%$ A (2 - $15 \mathrm{~min}) ; 70 \%$ A decreased to $3 \% \mathrm{~A}$ (15-18 $\mathrm{min})$; and $3 \% \mathrm{~A}$ (18-26 min). The mass spectrometer was operated in a dual scan mode with an initial full scan MS (200 - $800 \mathrm{~m} / \mathrm{z})$ segment followed by a secondary MS/MS scan (relative collision energy of 32) of the most abundant ion from the first scan. Peak areas for quantitation of usaramine were obtained from reconstructed ion chromatograms from the full scan MS data for the protonated molecule at $m / z 352$.

To confirm the identity of alkaloid in the sample of $C$. incana the isolated alkaloid was compared to a standard sample of usaramine previously isolated, and its identity verified by nuclear magnetic resonance spectroscopy analysis [13], and found to have the identical retention time and mass spectrum from both the above described liquid chromatography-mass spectrometry method and by a separate gas chromatographymass spectrometry method [7] to that of usaramine.

Chemical analysis of $C$. incana identified usaramine and usaramine $\mathrm{N}$-oxide (Figure 2) as the major pyrrolizidine alkaloids. Concentration of the alkaloids ranged from $10 \mu \mathrm{g} / \mathrm{g}$ in the leaf material to $870 \mu \mathrm{g} / \mathrm{g}$ in the seed. The $N$-oxide accounted for $40 \%$ of the alkaloid in the leaf and $10 \%$ in the seed. The chaff (seed pod minus the seeds) contained $220 \mu \mathrm{g} / \mathrm{g}$ total alkalid with $22 \%$ as the $N$-oxide.

The case occurred on June 2015 in Jaraguari County, Mato Grosso do Sul, Brazil (Latitude 2008'30'S Longitude 54 23'58'W). The affected

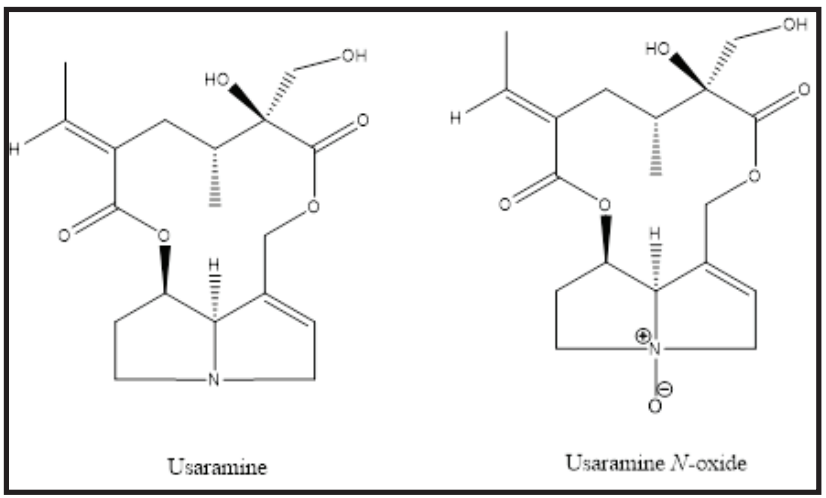

Figure 2. The major pyrrolizidine alkaloids identified in Crotalaria incana of this study were usaramine and usaramine N-oxide.

steer was part of a herd of 80 two-year-old steers that were transferred 30 days ago from Property 1 to Property 2.

Heavy presence of $C$. incana with signs of being consumed by the steers, was observed in a 258 ha pasture of Property 1 where 88 steers $(0.34$ steers per ha) were held for 6 months in continuous grazing. The pasture consisted of $53.9 \%$ of Brachiaria humidicola (5.6\% accounted for the leaves, $1 \%$ for the stem, and $45.6 \%$ of dead organic matter) and $46.1 \%$ of C. incana.

Two days after entering Property 2 one of the steers was observed staggering, depressed and with loss of weight. Fifteen days after the onset of the disease the clinical signs deteriorate. For the next 15 days, the steer stayed in sternal recumbency, oblivious to the environment and with the head turned and touching the thoracic cavity and eventually died 20 days after the onset of the clinical signs and was necropsied.

Significant necropsy findings were limited to the liver which was markedly enlarged and with rounded edges. The Glisson's capsule was thickened by focally extensive fibrotic areas. The hepatic cut surface was mottled with dark red parenchyma intercalated by extensive orange colored and markedly firm areas (Figure 3). Gallbladder was distended and the bile was inspissated.

Microscopically, the liver had the periportal parenchyma partially obliterated by fibrotic connective tissue with extended to other portal triads (bridging fibrosis) [Figure 4]. There was bile duct hyperplasia but occasionally the bile ducts were obliterated by fibrosis. Surviving hepatocytes were vacuolated (fatty degeneration) and extensive cholestasis was apparent (Figure 5). Moderate hepatocellular megalocytosis and bi-nucleated hepatocytes were observed. The Glisson's capsule was markedly thickened by fibrosis 


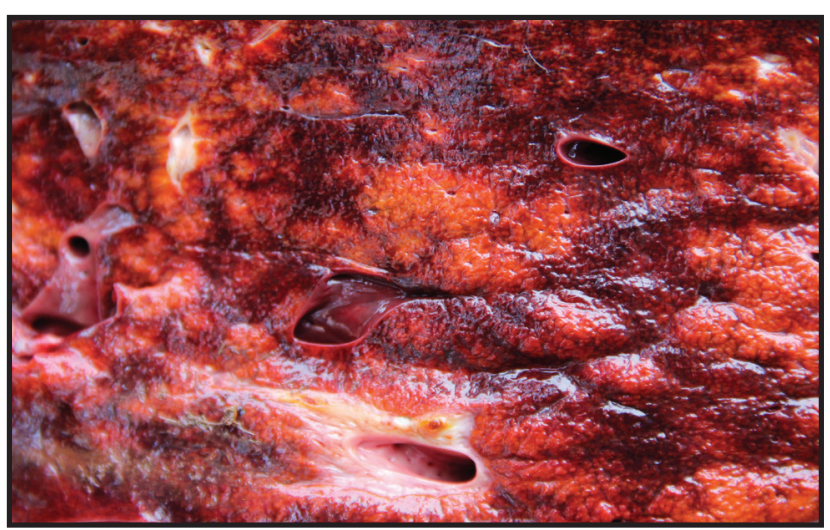

Figure 3. Bovine. Liver. Cut surface of the liver mottled with dark red parenchyma intercalated by extensive orange colored and markedly firm areas.

In the brain, there was vacuolation of myelin sheaths (status spongiosus) observed mainly in the brain stem and at the junction of the cerebral grey matter and subcortical white matter of the frontal, parietal and occipital telencephalon, and basal ganglia (Figure 6 ). Additionally, there were moderate gliosis and rare Alzheimer type 2 astrocytes.

\section{DISCUSSION}

The diagnosis of intoxication by $C$. incana in the steer of this report was based on clinical signs and pathological changes. Those are similar to the ones describe in the poisonings in cattle with this [15] and other [2,6] species of Crotalaria. The evidence of the plant being consumed by the steers is also indicative. The chronic characteristics of the lesions and the fact the onset of clinical signs occurred only two days after the introduction of the steers in Property 2 indicate that the intoxication happened by the consumption of $C$. incana while steers were grazing in Property 1.

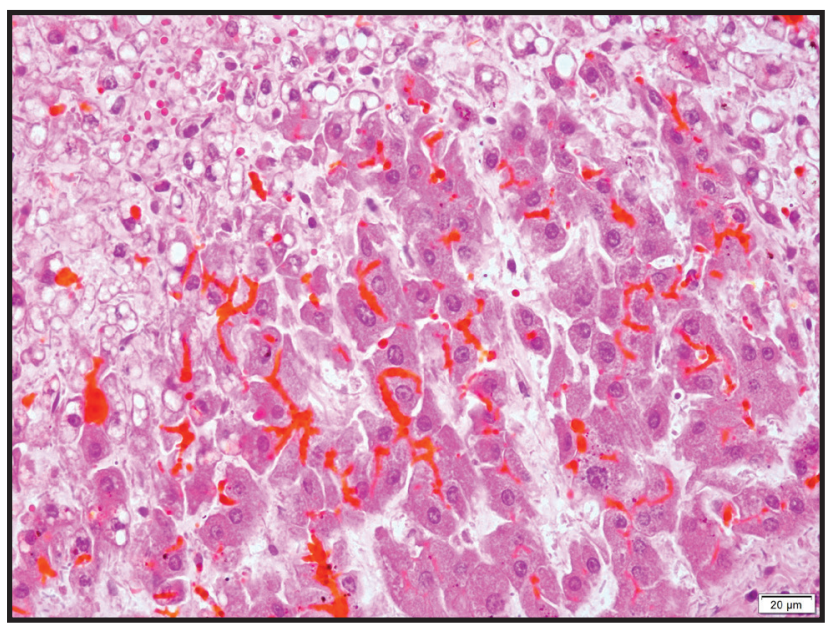

Figure 5. Bovine. Liver. The hepatocytes (top left) are vacuolated (hepatic degeneration). Notice the extensive cholestasis. [H\&E Bar $=20 \mu \mathrm{m}]$.
The high infestation of $C$. incana in the pasture, the high proportion of dead matter and the low concentration of viable leaves of $B$. humidicola most likely favored the ingestion of $C$. incana. The percentage of steer per ha was 0.34 which is lower than those reported elsewhere for poisoning by $C$. incana [15] and by C. mucronate [16] which were 0.92 and 13.45 respectively. This latter fact might explain why just one steer died in the situation currently reported.

Spongy degeneration, a typical lesion of hepatic encephalopathy, was observed in the brain of the bovine of this report. It was more severe in cerebellar peduncles, mesencephalon, thalamus, and pons as is previously recorded for ruminants [9]. Morphological changes in hepatic encephalopathy in the central nervous system of human beings and horses centers on astrocytes [5,8] which undergo Alzheimer type 2 change developing an enlarged, pale nuclei with a rim of chromatin and prominent nucleoli. Astrocytes pairs and triplets are seen, and, in severe cases, astrocytic nuclei may become lobulated and contain glycogen [8]. Cirrhosis of the liver as seen in the case of this report, results in elevated ammonia levels in the blood - and eventually in the brain - and ammonia toxicity which is the leading hypothesis for the causation of hepatic encephalopathy [8]. An astrocytic phenotype similar to Alzheimer type 2 changes can be induced by hyperammonemia in experimental animals and tissue culture and is also seen in human patients with congenital hyperammonemia due to inherited disorders involved in the urea cycle [4].

Morphological findings in ruminants with hepatic encephalopathy are characterized by microcavitation

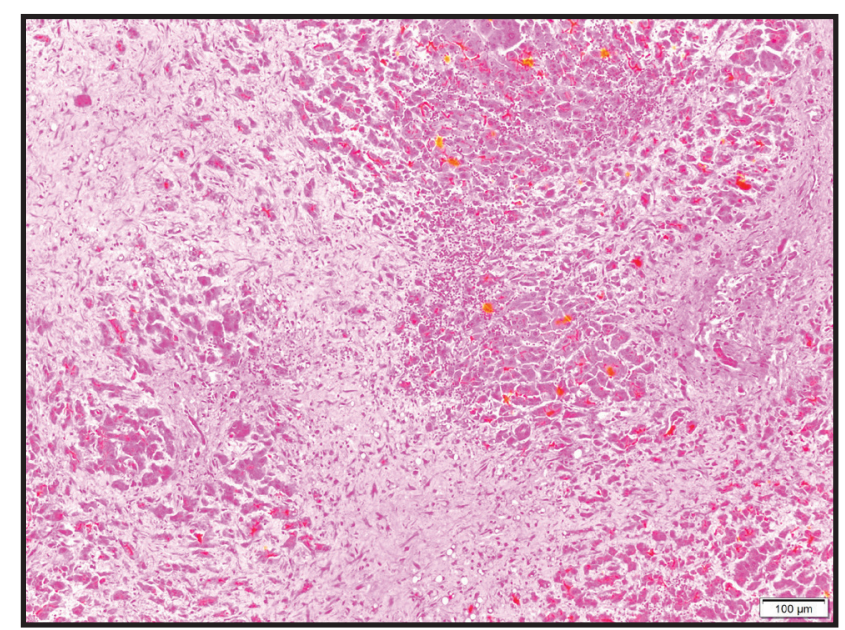

Figure 4. Bovine. Liver. Multifocal areas to periportal fibrosis coalescent (bridging fibrosis). [H\&E Bar= $100 \mu \mathrm{m}]$. 


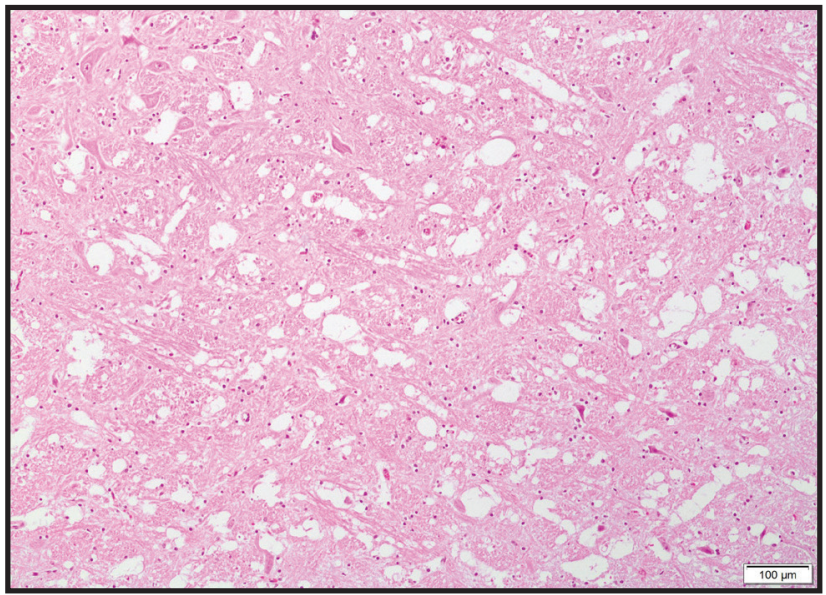

Figure 6. Bovine. Brain, vacuolation of myelin sheaths (status spongiosus). This lesion was mainly found in the brain stem and at the junction of the cerebral grey matter and subcortical white matter of the frontal, parietal and occipital telencephalon, and basal ganglia. [H\&E Bar= $100 \mu \mathrm{m}]$.

of the white matter in the brain, the so-called status spongiosus or spongy degeneration [8]. The spongy change is due to intramyelinic edema, causing splitting and vacuolation of myelin sheaths [8] and should be differentiated from a primary disease of the central nervous system in cattle.

The 1,2-dehydropyrrolizidine alkaloid usaramine, as well as the $\mathrm{N}$-oxide, were identified as the major alkaloids in the collected plant material and is consistent with previous findings of this alkaloid in C. incana $[1,10]$. C. incana has also been reported to contain the alkaloids integerrimine [1] and anacrotine [11] neither of which could be identified as present in this collection of $C$. incana. The concentration found in the seed $(870 \mu \mathrm{g} / \mathrm{g})$ was consistent with that previously reported of $700 \mu \mathrm{g} / \mathrm{g}$ [17]. Usaramine is structurally a macrocyclic diester of retronecine and therefore is predicted to be among the group of most toxic dehydropyrrolizidine alkaloids [12].

\section{MANUFACTURERS}

\author{
${ }^{1}$ Sigma-Aldrich. St. Louis, MO, USA. \\ ${ }^{2}$ Agilent Technologies. Santa Clara, CA, USA \\ ${ }^{3}$ Pharmco. Shelbyville, KY, USA. \\ ${ }^{4}$ Thermo Fisher Scientific. San Jose, CA, USA. \\ ${ }^{5}$ Phenomenex Inc. Torrance, CA, USA.
}

Acknowledgements. This work was funded by the Fundação de Apoio ao Desenvolvimento do Ensino, Ciência e Tecnologia (FUNDECT) do Estado de Mato Grosso do Sul (FUNDECT/CNPq - Grant 15/2014 - PRONEM -MS - Grant 59/300.126/2015). and by the FUNDECT do Estado de Mato Grosso do Sul (FUNDECT/CAPES no. 05/2014 - PVMS $59 / 300.032 / 2015)$. P.V. Leal is funded by a fellowship from FUNDECT (N³/2017).

Declaration of interest. The authors report no conflicts of interest. The authors alone are responsible for the content and writing of the paper.

\section{REFERENCES}

1 Asres K., Sporer F. \& Wink M. 2004. Patterns of pyrrolizidine alkaloids in 12 Ethiopian Crotalaria species. Biochemical Systematics and Ecology. 32(10): 915-930.

2 Boghossian M.R., Peixoto P.V., Brito M.F. \& Tokarnia C.H. 2007. Aspectos clínico-patológicos da intoxicação experimental pelas sementes de Crotalaria mucronata (Fabaceae) em bovinos. Pesquisa Veterinária Brasileira. 27(4): 149-156.

3 Bull L.B. 1955. The histological evidence of liver damage from pyrrolizidine alkaloids: Megalocytosis of the liver and inclusion bodies. Australian Veterinary Journal. 31(2): 33-40.

4 Butterworth R.F. 1993. Portal-systemic encephalopathy: a disorder of neuron astrocytic metabolic trafficking. Developmental Neuroscience. 15(3-5): 313-319.

5 Crawford J.M. 2005. Fígado e trato biliar. In: Kumar V., Abbas A.K. \& Fausto N. (Eds). Robbins e Cotran Bases Patológicas das Doenças. 7th edn. Philadelphia: Elsevier, 924p.

6 Cullen J.M \& Stalker M.J. 2016. Hepatic dysfunction. In: Maxie M.G. (Ed). Jubb, Kennedy, and Palmer. v.2. 6th edn. St. Louis: Elsevier, pp.290-295.

7 Gardner D.R., Thorne M.S., Molyneux R.J., Pfister J.A. \& Seawright A.A. 2006. Pyrrolizidine alkaloids in Senecio madagascariensis from Australia and Hawaii and assessment of possible livestock poisoning. Biochememical Systematics and Ecology 34(10): 736-744.

8 Harris J., Chimelli L., Kril J. \& Ray D. 2008. Hepatic encephalopathy. In: Love S., Louis D.N. \& Ellison D.W. (Eds). Greenfield's Neuropathology. v.1. 8th edn. London: Hodder Arnold, pp.693-694.

9 Hooper P.T. 1975. Spongy degeneration in the central nervous system of domestic animals. II. Chemical analysis and vascular permeability studies. Acta Neuropathologica. 31: 335-341. 
10 Martins C.H.Z., Cunha, B.P., Solferini V.N. \& Trigo J.R. 2015. Feeding on host plants with different concentrations and structures of pyrrolizidine alkaloids impacts the chemical-defense effectiveness of a specialist herbivore. PLOS One. 10(10): 1-27.

11 Mattocks A.R. 1986. Chemistry and toxicology of pyrrolizidine Alkaloids. New York: Academic Press, p.196.

12 McLean E.K. 1970. The toxic actions of pyrrolizidine (Senecio) alkaloids. Pharmacological Reviews. 33(4): 429-483.

13 Neto T.S.N, Gardner D., Hallwass F., Leite A.J.M., Almeida C.G., Silva L.N., Roque A.A., Bitencourt F.G., Barbosa E.G, Tasca T., Macedo A.J., Almeida M.V. \& Giordani R.B. 2016. Activity of pyrrolizidine alkaloids against biofilm formation and Trichomonas vaginalis. Biomedicine and Pharmacotherapy 83(7): 323-332.

14 Neuman M.G., Cohen L.B., Opris M., Nanau R. \& Hyunjin J. 2015. Hepatotoxicity of Pyrrolizidine Alkaloids Journal of Pharmacy \& Pharmaceutical Sciences. 18(4): 825-843.

15 Queiroz G.R., Ribeiro R.C.L., Flaiban K.K.M.C., Bracarense A.P. \& Lisbôa J.A.N. 2013. Intoxicação espontânea por Crotalaria incana em bovinos no norte do estado do Paraná. Semina. 34(2): 823-832.

16 Tokarnia C.H., Döbereiner J. \& Peixoto P.V. 2002. Poisonous plants affecting livestock in Brazil. Toxicon. 40(12): 1635-1660.

17 Williams M.C. \& Molyneux R.J. 1987. Occurrence, concentration, and toxicity of pyrrolizidine alkaloids in Crotalaria seeds. Weed Science. 35(4): 476-481. 